\title{
Back on the Barricades: New Feminisms and Market Innovation in the Consultancy Field
}

\author{
Magdalena Petersson McIntyre ${ }^{1 *}$
}

Published: September 1, 2021

\begin{abstract}
The enhanced role given to innovation in capitalist societies has resulted in a development where even matters such as gender equality are assessed and rewarded based on their innovation potential. Markets, innovations and companies are believed to possess and offer solutions to gender inequalities, a development that relies on the commodification of gender equality. This paper is based on an ethnographic study of the field of gender equality consultancy with the aim of critically investigating the belief that gender inequality can be solved with innovations. Focusing on clients, market demand, innovative and sellable solutions, and profits, gender consultancy illustrates how markets have become a model for equality work. The interviewed consultants created new products, thought up new words and concepts, and emphasised gain for the client. Innovation discourse iterates technocratic approaches to social and cultural problems. However, the paper argues that innovation discourse is a 'doing' that is open for re-configuration. By searching for new business models based on the principle of 'together in ways that matter', the interviewed consultants also worked to contribute to a more equal and fair society. Thus, the commodification of gender equality simultaneously opens up possibilities to re-code and reappropriate the concept of 'innovation'.
\end{abstract}

Keywords: gender equality consultants, market feminism, economic performativity, gender and innovation, commodity feminism

\section{INTRODUCTION}

'Such neoliberal bullshit!' That is what the lecturer in gender studies said when we were invited to speak to their students. How should we respond to resistance [like that] and [explain] why we have joined the 'bad' side? (Elisabeth, gender equality consultant).

Innovation is considered to be a universal solution to present-day concerns such as securing economic development and growth, solving climate and health crises, and ending poverty and inequalities. As argued by Beckert (2016), innovations are a cornerstone of capitalist dynamics: 'Capitalist growth is driven by the introduction of new products, more efficient production methods, and the expansion of the realm of market exchange' (Beckert, 2016: 169). The enhanced role that is given to innovation in capitalist societies has resulted in a development where even matters such as gender equality are assessed and rewarded for their innovation potential. Markets, innovations and companies are increasingly believed to possess and offer solutions to inequalities. This is particularly the case in Sweden, the context of this study. This development relies on: (a) the belief that economic growth is the ultimate goal of everything; and (b) the transformation of 'gender equality' into a product or service through a process of commodification. The Swedish governmental innovation agency, Vinnova, for instance, regularly calls for funded 'Innovations for increased equality' in which actors are invited to collaborate and explore the 'potential of how new solutions to gender equality and/or diversity challenges can help achieve other goals in Agenda 2030'. ${ }^{1}$ Sweden is a country with a strong tradition of (male) industrialism and likes to praise itself for its entrepreneurial spirit and business climate.

Still, gender equality is rarely placed on policy makers' agendas when need for innovation is brought up. On the Swedish government's homepage, innovation is defined as 'new or improved solutions that create value for

${ }^{1}$ https://www.vinnova.se/en/calls-for-proposals/normkritisk-innovation/preparation-projects/. 
society, businesses and individuals'. Furthermore, it is also described as a means to secure sustainable development, fight unemployment, and create value for individuals. ${ }^{2}$

The underrepresentation of women in the context of entrepreneurship and innovation has been recognised as a problem and has led to several state initiatives which have the goal to encourage women to engage in business. As argued by Ahl et al. (2014), governments in the Nordic countries recognise entrepreneurship as the engine of economic growth and see women as an untapped resource that can be used to further economic growth. Programs that are intended to stimulate women's entrepreneurship have consequently been implemented. However, the success rates of these programs have been low, and scholarly critique of women's entrepreneurship programs has been somewhat merciless (Ahl et al., 2014; Berglund et al., 2018).

The present article is based on an ethnographic study of the field of gender equality consultancy, where I critically examine the idea that gender inequality can be solved by innovations. I examine a group of professionals who operate within a market that addresses issues of feminism and gender equality, and who regularly have to deal with increased demands on issues of gender equality to be innovative. However, I will argue that these professionals also work innovatively to contribute to a more equal and fair society. The title, 'back on the barricades', is taken from my fieldwork experience and refers to how some of the gender equality consultants whom I interviewed described the work that they do. This article thus discusses why the 'barricades' symbolically deployed in the late 2010s are referred to as a matter of entrepreneurship and business, and the impact of innovation discourse on the organisation of equality measures. The following remarks by another gender equality consultant, Elisabeth, ${ }^{3}$ illustrate the tensions that exist in the field of feminism and gender issues concerning working in a private marketplace, and how those individuals who do work under such conditions choose to deal with those tensions (cf. Kunz and Prügl, 2019). Many of the interviewed consultants in this study felt that their work was questioned or criticised by activists and academic gender scholars who thought they had 'sold out'. As Elisabeth declared: '[w]e can't be as nuanced as theories, the alternative is to do nothing at all'. The purpose of this study is to examine how gender equality has become a commodity and how this commodification is practised and understood in the context of consultancy work. Further, I investigate whether the work that consultants do can be understood in terms of innovations and what the consequences of such a view are. The contribution that this paper makes is twofold: (1) it problematises innovation discourse for its iteration of technocratic approaches to social and cultural problems; and (2) it examines the potential to re-code and reappropriate the concept of 'innovation'. Beckert (2016) demonstrates how, with the advent of capitalism, technologies that had remained constant for centuries began to change rapidly. Innovations satisfy previously unmet needs and create new ones, make the production process more efficient, and provide firms with opportunities for profit. Beckert understands innovation in terms of fictional expectations, utopian visions of a pretended future reality; he terms this 'imagined futures'. As also argued by techno-feminists such as Wajcman (2004), decisions made by entrepreneurs and firms cannot be explained in terms of optimisation since there is no way to determine what an optimal investment in innovation would be. Decisions about innovative activities themselves create the future since 'competition in capitalist economies is in no small measure a struggle over imaginaries of future technologies' (Beckert, 2016: 170).

\section{THE COMMODIFICATION OF GENDER EQUALITY}

The term social innovation has been used to refer to and promote inclusive processes and solutions that address societal challenges (Lindberg, 2017). However, social innovation can also be seen as an outcome of the influence of innovation discourse on matters that are remote from the context of engineering (i.e., the context in which innovation is largely used). In the context of gender and feminism, terms that deal with inequalities from the perspectives of innovation and market exchange range from 'femvertising', referring to advertising with feminist content, to 'norm-creative innovation' - a concept that tackles inequalities as inefficient and views gender equality as ways of optimising organisations so that they can perform to their best potential. Many scholars have criticised these undertakings for draining feminism of its critical edge and content. Ahl et al. (2014) coined the term FemIncIsm to capture the phenomenon of 'feminist activism through enterprise' which they describe as the use of entrepreneurship to achieve feminist change, an endeavour which they see as possessing potential, but is difficult to achieve. By focusing on representation instead of a gendered redistribution of power and wealth, FemIncIsm puts the entrepreneurial individual's right to freedom and to contribute to economic growth above collective struggle, it is argued (Berglund, et al., 2018). Furthermore, terms such as 'commodity feminism' (Dworkin and Wachs, 2009; Goldman, Heath and Smith, 1991) and 'post-feminism' (McRobbie, 2009; Negra and Tasker, 2007) have been used to critically discuss the emergence of new forms of feminisms where women's empowerment is located in the domains of consumption, lifestyle, and entrepreneurialism, instead of being seen as a matter of state equality

2 https://www.government.se/government-policy/innovation/ (accessed 9 September 2020).

3 All names have been anonymised.

$2 / 15$

(C) 2021 by Author/s 
initiatives. The term 'post-feminism' has also been used to critique a subsequent blurring of the relationship between femininity and feminism, and the lack of critical content or edge in narratives of consumption, lifestyle and entrepreneurialism (cf. Gill, 2017; Scharff, 2018).

A related development to the above is the recognition that work on inclusion and diversity can be motivated by the hope for positive outcomes for brands and organisations. A large body of literature on diversity in organisations elaborates on this theme, both for practical use and as a topic of critique. De los Reyes and Mulinari (2005) argue that the concept of 'diversity' un-problematically celebrates the benefits of diversity while maintaining unequal conditions for members of society. It ['diversity'] achieves this by linking the participation of minorities in organisations to demands of profitability, thus setting up special conditions for their participation.

Organising issues of welfare and equality in terms of markets has not avoided further interrogation. Brown $(2015,2003)$ terms this process 'the stealth revolution of neoliberalism'; referring to what she describes as the production of everything in the image of a market, and the dangerous outcomes when democracy itself turns into a marketplace. Brown approaches neoliberalism as a structural as well as an ethical element, assuming that neoliberalism does not only change the role of markets but also people's ways of making sense of their lives (see also Lewis, Benschop and Simpson, 2017: 7; du Gay, 2007). The consultants included in this study constantly struggled to make themselves employable by improving their products and services, as well as their selves. Feminist knowledge was conceived as an asset for entrepreneurship and the feminist subject as 'malleable' (Lewis, Benschop and Simpson, 2017: 14). In theories of subjectivity and work that are inspired by Foucault, the concept of 'entrepreneurship of the self has been used to denote the emergence of an entrepreneurial subjectivity that is interwoven with a neoliberal ideology (McNay, 2009; Du Gay, 2006; Foucault, 1988). Neoliberalism is then seen as a 'governmentality', that is more than the principles of free-market forces, and includes the organisation of subjectivity (Petersson McIntyre, 2014).

\section{Gender entrepreneurialism}

Other commonly used terms in the literature on professional groups that are similar to the group studied in this article, whom I call 'gender equality consultants', are titles such as femocrats, professional feminists, and gender experts (cf. Kunz and Prügl, 2019; Kantola and Squires, 2012). In line with a critique of neoliberal forms of governance, the emergence of these professional groups has been criticised for reducing feminism to measurable goals, checklists, tool-kits, gender-washing, and statistics (Kunz and Prügl, 2019; Ovidius and Rönnblom, 2019). With its clients, market demand, innovative and sellable solutions, and profits, gender consultancy clearly illustrates how markets have become a model for the implementation of equality. By turning to 'performativity' theory, I will, however, take a particular approach to this phenomenon.

\section{PERFORMING THE ECONOMY DIFFERENTLY}

In the field of gender studies, the term 'performativity' has primarily been associated with Butler's (1990) theories of gender performativity, in which gender is theorised as 'a kind of becoming or activity ... an incessant and repeated action of some sort' (Butler, 1990: 112). In the field of new economic sociology, however, performativity theory has also been used to understand economics (or markets) as constituted by materialdiscursive enactments (Cochoy, Giraudeau and McFall, 2014). According to Callon (1998: 2), '[e]conomics, in the broad sense of the term, performs, shapes and formats the economy, rather than observing how it functions.' How we think about the economy is part of creating that economy.

In the theories of Gibson-Graham (2015), a post-structuralist Foucauldian concept of 'a technology of the self' is applied to refer to the way individuals 'effect by their own means or with the help of others a certain number of operations on their own bodies and souls, thoughts, conduct, and way of being, so as to transform themselves' (Foucault (1997: 225) in Werner, 2015: 83). These scholars combine this view with a performativity perspective on the economy, for the creation of economies that are fashioned in 'different ways that matter' (Gibson and Scott, 2019; Gibson-Graham, 2006; Roelvink, Martin and Gibson-Graham, 2015; 1996). Part of this endeavour is to question how 'the economy' is viewed and represented, and disclose to others that there is a gendered nature to the narratives around economics. Gibson (Gibson and Scott, 2019) exemplifies the way production workers are seen as the 'real' workers in an economy, and their activities constitute the dynamics of an economy, while people who remain in their homes are seen as doing mere 'support work' or 'reproduction' work. Today, she argues, economies are primarily represented as financial sectors, which means people who do not have shares nor play the stock market do not feel they are part of the economy (Gibson, in Gibson and Scott, 2019: 3). Such an understanding is not 'the truth', but a representation, a narrative, or boundary-drawing practice.

Furthermore, one effect that representations have includes making us see certain kinds of market dynamics as more important and more influential than others, thus allowing for and encouraging specific (select) forms of actions (Gibson and Scott, 2019: 2). The capitalist economy should not be seen as naturally 'given', but, instead, 
should be viewed as performative and a 'doing'. To counter-perform, to act on, think about, and organise in ways that counter conventions for economic activity can open up different ways of creating economies in ways that matter. I will argue that the activities of the consultants that I studied can be interpreted in this way. Thus, this perspective talks of directions for change, and for transforming the thinking around matters of the economy in order to produce more ethically grounded ways of being and acting. As articulated by Werner (2015: 77_ 78), 'Gibson-Graham deconstructs capitalocentric discourse and, embracing on ontological politics, propose an alternate set of economic assumptions, questions, and research agendas, namely that of diverse economies, with a focus on ethical practices that fall under the rubric of community economies.' Healy (2015: 113) notes that this approach allows us to see economies as 'constituted through ideas and matter, relationships and systems of accounting', and thus also suggests that 'these assemblages are open to being reconfigured'. Therefore, as well as delineating ways in which we can redefine definitions of economic practice, this perspective also helps us to shift course. Instead of focusing on how neoliberalism produces an entrepreneurial self, the focus can be shifted to examining the possibilities for the formation of a self that desires an economy that matters.

The studies that have been inspired by Gibson-Graham are primarily empirical studies of the food and/or agricultural industries. Such studies have examined the creation of so-called 'community economies' and discuss the possibilities for the creation of different, and more ethically-grounded, ways of organising the supply of food, thereby creating alternatives to markets that already exist (see also Geiger et al., 2014). Despite these apparent differences with the work that is done by gender equality consultants in Sweden, I suggest that the comparison has relevance. I claim this because this comparison allows for an understanding of the work that gender consultants do as performative acts, acts that open up innovation discourses for re-configuration by pointing towards a direction for change. Even if the gender consultants included in this study did not always report that they wished to form an alternative economy or a community economy, in a strict sense, they described their activities as a way of transforming an economy from within. Instead of detaching themselves from capitalism, the consultants wanted to be included. They had previously felt excluded and felt that their perspectives had been excluded.

\section{METHODS}

In-depth interviews were carried out with 22 consultants between 2016 and 2020, all of whom are operative in a market that addresses issues related to gender, gender equality, diversity, inclusion, 'norm-critique', and sexuality. Two of the interviewees identified as 'male' (one from a transgender perspective), and the rest of the consultants included in this study identified as 'women' (although many of the interviewees were critical of binary gender definitions and heteronormativity). Most of them had a Swedish or Nordic background. They were based in major Swedish cities, but regularly travelled around the country to do jobs.

Qualitative ethnographic methods were chosen in order to gain insight into the consultants' reported experiences and relate these insights to discourses on entrepreneurship and innovation. During the course of my investigation, I was able to identify several cultural patterns, values, relations, and meanings that (in)form the thinking around the relationship between gender equality, feminism, markets and innovation (Ehn and Löfgren, 2009; Ehn, Löfgren and Wilk, 2016; O’Reilly, 2003; Pink et al., 2016). Participant observations were also carried out during the training of new consultants and in activities with clients, meetings, workshops and lectures. I followed a closed Facebook group, read webpages and materials such as the books written and used by consultants, and also examined some tools that are used by the consultants, such as card games. Four of the consultants were interviewed together in a group interview, referred to in one quote as 'Group of Consultants'. The interviews were recorded and transcribed.

I asked all the interviewees to describe the field of gender consultancy in Sweden and identify firms and individuals that they either knew or found prominent in the field. This information gave me a good overall picture of some general tendencies that exist in the field of gender equality consultancy. Many of the consultants also shared their opinions on perspectives in the field. Frequently, these were perspectives which they disagreed with, and I quickly identified that some form of tension existed between certain groups of consultants, typically in relation to (perceived) attitudes towards profits and different approaches to doing business.

The consultants could be categorised as belonging to three different groups. The first group was businessoriented and interested in recruiting clients from private companies, in helping them with ad campaigns, product design, or modifications to their work environment. The second group was more oriented towards promoting gender equality and gender mainstreaming in public administrations, such as universities, municipalities and hospitals. The third group consisted of individuals who gave talks about their private experiences, including topics such as 'sex on equal terms' and 'non-binary experiences'. Just under half of the interviewees belonged either to the first or the second group, whilst only two individuals (2 out of 22) fell under the third category. The consultants who fell under Group 1 were typically a little younger than the consultants in the other two groups. They also had previous experiences of entrepreneurship, even if not personally, and often held university degrees in gender 
studies or social sciences and humanities. Group 2 and Group 3 typically had work experience from schools, hospitals and NGOs, and many of them held university degrees in behavioural, educational, or social sciences. However, the differences between these two groups were not clear-cut. The interviewees all had some form of self-employment or employment in a private company, or both. At times, this was combined with employment in the public sphere. Some of the consultants had provided consultancy services for 30 years, while others were new to the field.

\section{WHAT DO GENDER CONSULTANTS DO?}

To contextualise the findings of this study, I begin by giving a presentation of what gender equality consultants do. Their work is primarily organised in the form of assignments of varying budgets and durations. An assignment could consist of, for example, a lecture or a series of lectures; workshops; evaluations; a survey; and/or a written report. Some of the informants perform 'gender mainstreaming' in public administrations (surprisingly, often at universities). The consultants reported that their clients generally expected them to suggest 'improvements'.

Other frequent assignments include providing feedback on recruitment and communication strategies. This entails offering input on visual campaigns, ad campaigns, or information campaigns. Occasionally, work assignments consist of a more general analysis of the workings of norms in an organisation, from its lunch-room culture and the jargon used by employees, to attitudes amongst management. Some consultants had clearly defined methods and offered ready-made packages, whilst others were more open to their clients' wishes and so would adapt their services accordingly.

Some of the consultancy firms included in this study were explicitly interested in private enterprise. These firms often made the notion of profit and opportunities for making a profit quite clear on their home pages. They were creative in their efforts to make a living out of gender issues and organised courses, Christmas parties, and different forms of get-togethers, thereby constantly innovating their market products.

The interviewees often felt that it was challenging to explain in simple terms what they could offer to their clients. As noted by Kunz and Prügl (2019: 7), it is something of a paradox to combine feminism's rejection of hierarchical categorisations with the role of expert. In fact, many of the consultants struggled with this, both on a personal level and in relation to selling a service to a potential client. They claimed that having a clearly defined issue for an assignment was one way of overcoming this, along with finding ways of 'explaining to corporate people the opportunities and consequences of our services as simply as possible', as put by for instance Rita during the interview. They thought, for instance, that focusing on communication strategies and examining written and visual materials on recruitment or employee branding was a good method to use to define a job. The consultants would then offer suggestions on how the client could become 'more inclusive' in their communication strategies. Comparing the numbers of men and women at different levels of an organisation with the goal of 'gender mainstreaming' in mind was another way of delivering a service. Another method of turning gender equality into a commodity was to create something new in material form. This would be made manifest in the form of visual communication more often than in three-dimensional object form, even in attempts to create norm-critical product design (see semcon.com/sv/addperspectives; cf. Petersson McIntyre, 2015, 2018).

Clients often had doubts about what the product being sold to them really was. Almost all of the interviewees reported that the biggest challenge that they faced was that clients know very little about what they want and what the consultants can do for them. Furthermore, the clients demonstrated 'unrealistic' expectations concerning their budgets. Clients know that they need or know that they should do 'something' about 'the gender thing', but not quite why, how, or what, the consultants reported. Similarly, clients had no idea of how their expected improvements were going to be implemented. Elina raised this point:

Often you are contacted by someone who says their boss wants something done in the field, and then they don't know what that is, but they still have to make it happen. And then you start one way, and halfway through they change their mind and want something else. Middle hands who don't know what they want, that is the worst. Someone has been told by someone else to do something about 'the gender thing'. Often in public administrations, universities. That is why private industry is so much more fun. You only hear from them if they are serious, if they have the need. It's great, and the process is much faster! Private industry has a more specific goal.

Elina's comments show the increased significance that has been given to gender equality in both public and private organisations in Sweden. However, they also indicate that the reasons why gender matters are important are not always understood, not agreed upon, and subject to bureaucratic processes (cf. Alnebratt and Rönnblom, 2016). 


\section{GENDER IN THE FIELD}

Turning gender into a commodity was difficult in several ways, and gender, as a cultural process, manifested itself in different forms in the field. A vast majority of the gender consultants are women, and 'gender'/femininity, or non-cis-masculinity, in terms of belonging to a disadvantaged group, was something most of them represented with their bodies and their identities. They were self-employed, not so much out of choice as out of necessity, since being self-employed was the only way for them to make a living out of gender issues. They were entrepreneurs of the self, and many of them were critical of regular work life and said they wanted a 'different life'. They themselves were the products of a gender-segregated education system and work life, and they tried to make a living out of their knowledge/convictions and the cultural position that was given to them. In this way their commodity was 'embodied'. 'Gender' was also the product or service they were selling. Consequently, the consultants needed to make a distinction between their personal goals, and the usefulness of their product, even if, at times, their personal experiences helped to do this. Thus, gender identity was something they represented, but also something they tried to create a professional distance from, in order to explain in neutral and objective terms 'how it works'. They were therefore able to make gender into a commodified 'thing' - something that could be sold and bought. While doing this, the consultants also felt the influence of prevailing gender structures in their daily encounters with their clients. Male consultants generally enjoyed more authority; something that was both reported on during the interviews and something that I noticed during my observation sessions. This meant that the female consultants had to try to sell services to improve inequalities in organisations while at the same time feeling that their clients trusted their male colleagues/competitors more.

Furthermore, the male consultants were often paid more for their services or worked for higher paid jobs. The less jobs pay, the higher the percentage of women doing those jobs, they argued. Thus, working as a gender consultant involved both making 'gender' into a commodity, and dealing with the commodified 'thing' that gender is made into, often in relation to one's own body. In the following sub-sections, I discuss how the interviewees dealt with commodification. It was a constant process, as put by Cameron (2015), of bringing things together, of making interdependencies visible, and challenging divisions.

\section{Creating a Product}

During my fieldwork, I visited the communications and advertising office of a major department store with a group of gender equality consultants. The client wanted input on an upcoming campaign and to 'go from being liked to being loved', their marketing department explained. Improving their communication strategies with the help of gender consultants was part of this process. This client also wanted to appear genuine, inclusive, diverse and a little 'cutting-edge', they explained. Their target group was 'an aware woman in the middle of her life'. During the meeting, we were presented with an upcoming campaign for a special calendar day, and the consultants were commissioned to give feedback on this campaign. It had already been agreed that the consultants' feedback was going to be in terms of the possible risks and benefits of the suggested campaign. In this context, the client raised the following questions: 'What kinds of reactions did we [the consultants] think the campaign might result in?' 'How should they [the client] respond to those reactions?' 'What actors/individuals may have an interest in promoting critical or supportive messages around the campaign?' After the meeting, the consultants and I discussed the importance of giving constructive feedback. The senior consultants encouraged the group to be positive and supportive, rather than critical. The assignment consisted of finding solutions to any possible risks that we could identify. Feedback was given to the client a week later. ${ }^{4}$

This assignment was a typical assignment since several similar situations were reported on during the interviews. Sometimes, the client was proud to show what they had accomplished together with the consultants, whilst on other occasions, the consultants were backstage, pretending that they were not involved at all, several of the interviewees said. A company might, for instance, want to use a transgender person in a campaign, but might also want input on this decision and a list of Q\&As for how to deal with potential reactions from the general public, they explained. Elvira, one of my interviewees, described what they do in such cases:

We help them, how can such an image get attention 'without making a thing out of it'. We don't want to say 'we are fantastic for showing a transgender woman'. We give recommendations for how to do it right.

Other examples that were brought up during the interviews described assignments in which clients asked for expertise on how, for instance, fashion models wearing hijabs should be represented visually, as well as how adverse reactions to such images should be met:

\footnotetext{
${ }^{4}$ Notes from the author's field diary.
} 
'How can we do it the right way?' How should they handle racist comments? We give support and help; we tell them what to say and what not to say. But sometimes you see in the media that they didn't follow our advice. And, of course, we can't anticipate every reaction.' [...] Sometimes, clients don't ask our advice and just go ahead. 'Then sometimes they come back later and say, 'okay, maybe we do need you'.

The consultants would present 'worst-case scenarios' and give examples of how to deal with angry reactions from the general public.

\section{Words}

An essential aspect of the process of commodifying gender equality was through the interviewees' careful attention to the words and concepts they used to describe their services. 'Gender' was itself far from an easily defined 'thing', commodity, or concept, but needed to be adapted to various situations. Different terms and concepts were used in the interviews and during my fieldwork. I suggest that (i) engaging with various linguistic representations, (ii) coining new terms, concepts, and methods, (iii) using language and words in targeted ways, and (iv) marketing products and services may be understood as ways of working innovatively. Further, how the consultants described the field in which they worked can be seen as an important part of working an innovation system. Words do not just describe reality. Naming gives one's work direction and (in)forms the thinking around what is being done. As pointed out by Gibson (2019:2), representations in language shape the ways we understand reality and affects how we act. Language performs the reality we operate in; it makes 'certain things more real and certain things less real' (Gibson, 2019: 2). This means that the words that the consultants use could also be put to use to enter new spaces, to perform work as innovative, key and economically dynamic.

'Gender', 'equality', 'sexuality', 'diversity', 'norm-critique' and 'inclusion' were concepts that were used by all the consultants. For some, the use of specific terms went through a chronological process. For example, historical developments have gradually favoured the notion of 'inclusion' over 'gender equality'. Ten years ago, the consultants would more readily invoke the concept of 'gender equality', but then came 'diversity', and now 'inclusion' is the more popular concept, they said. Note that the changing use of these concepts reflects the Swedish context and the concepts that were widely used in equality discourse at the time of the study. These historical developments are also related to changes in Swedish legislation (see the Swedish Anti-Discrimination Act of 2017). The act adds to the requirement to work with gender equality the requirement to work with all seven grounds of discrimination: ${ }^{5}$

Doris: It has changed so much. I have been working with these issues since 2012, and the way they are talked about has really changed. It used to be a matter of gender equality, followed by the term 'diversity'. Nowadays, really many use the term 'inclusion'.

Viola: Back then (10 years ago from 2019), gender mainstreaming was really the only thing one talked about, and everyone was at least half-employed by a public institution.

Elsa: You notice a big change. The way companies work with these questions has really changed. Consumers' awareness too. You can't make gender-discriminatory ads anymore. It doesn't sell. The change is enormous.

'Gender equality' was a contested term in many ways because some consultants thought that it should no longer be used and referred to critiques from advocates of the terms 'intersectionality', 'diversity', and 'inclusion'. For others, sticking to the same terms over time was seen as crucial. In fact, some consultants whom I approached for interview thought the correct use of terminology was so important that they declined to be interviewed after they had asked me for my definition of 'gender'. Apparently, I had not used the correct words. This illustrates existing conflicts in the field, typically between advocates of 'gender equality' and more post-structuralist definitions of identities (cf. Martinsson, Griffin and Giritli Nygren, 2016). Importantly, I observed that the terms that were used by the consultants were entangled in the nature of the services that they offer.

Many of the interviewees found the critique of heteronormativity and cis-normativity ${ }^{6}$ to be an imperative development, even on a personal level. Others, however, argued that concepts and theories are changeable, and either thought that it was not important which terms one used, or they emphasised the importance of 'keeping up'

\footnotetext{
${ }^{5}$ See https://www.do.se/other-languages/english/protected-grounds-of-discrimination/.

${ }^{6}$ Cis-gender is the opposite of transgender and means that a person's gender identity corresponds with the sex assigned at birth, from the Latin preposition 'cis' which means 'on this side of. Cis-normativity refers to the assumption that most individuals are cis-gender.
} 
with developments in the field, including terminological developments. For many of the consultants, the boundaries between the different words and concepts related to gender and feminism were fluid, and definitions change and might differ between individuals.

What the consultants called themselves also varied greatly. Surprisingly, often during my fieldwork, a consultant might say, 'I was the one who coined this term', referring to a particular designation, for example, 'gender expert'. However, some of the consultants said that they found the creation of different professional names problematic, and made a point of not branding themselves. An exclusively Swedish term that was brought to my attention was the term normingenjör ['norm-engineer'], which combines the masculine term 'engineer' with the idea that norms can be built and re-built. The term can be seen both as a reflection of the strong position that engineering, and innovation discourses have in Sweden, and the consultants consciously filling terms with new content. Normengineers sometimes compared themselves to medical doctors, another high-status occupation, as claimed by Paula: 'we make a diagnosis and work salutogenously (health-driven), to create health in this relation, between individuals and within organisations.'

\section{Focus on Inclusion}

The term 'inclusion' appeared particularly well suited to consultancy work and may thus be considered an innovation. Although inclusion is not a new term in itself, the interviewees' application of the term illustrates how terms can be adapted to function in specific contexts. As argued by Cecilia:

People find these issues complex and hard to talk about, and think: 'What is it good for?' or 'What's in it for me?'... But 'inclusion' is something everyone can relate to. Everyone can relate norms to themselves, and think, surely there is some norm that I have broken. And then you can get people to understand their own privileges too, and you get them on board in a different way. It is much easier to enter a discussion with someone who is sceptical and say: 'Let's talk about inclusion'. 'Well, who is going to be included?' 'Well, it could be you'.

By talking about inclusion in this way, the consultants presented it as something non-confrontational. The word is presented as involving a form of transformation, from making inequalities visible, such as in gender mainstreaming, to focusing on the inclusion of individuals' rights. Cecilia's argument illustrates how connections are formed between (i) the tools that are used by the consultants, (ii) the devices and words that they use, (iii) general political developments (legislated grounds for discrimination), and (iv) the way that the consultants made sense of who they are.

The consultants fully recognised the fact that words are significant as they worked to associate new meanings with words by using the domains of business and science as sources of signifiers. Developing a new language of economics, or finding new ways to describe the relationship between business and gender issues can, as suggested by Gibson and Scott (2019), be an essential part of imagining other ways of understanding the economy. Furthermore, this approach may be used in examining and understanding the politics of collective action in different ways (see also Gibson-Graham, 2006: 55-56).

One outcome of the commodification processes of gender equality was evident in how the consultants presented their services, or created products, by denying that it had anything to do with gender. As one interviewee, Doris, said, 'Diversity, norms and gender equality is knowledge and science. We want to show that we don't work with "soft" values, but pure and utter business development and sustainability'. It is, of course, difficult for selfemployed individuals to change the rules of the game solely by dint of their own effort. Trying out new terms, words and motivations can, however, be the first step in that direction. This experimental approach can be used to explore alternative ways of performing gender equality work. Healy (2015: 104-5) observes that in the context of a worker-owned cooperative, 'these experiments may succeed or fail, but in either case, they possess the potential to undermine the concept of economy as a monolith and to performatively open a space for the possibilities that come with economic difference.'

\section{Focus on Gain}

Disclaiming the idea that products and services are a matter of gender equality was most noticeable when the consultants emphasised the gains that could be enjoyed by the client (De los Reyes, 2016). The consultants emphasised the commercial benefits of gender equality and inclusion, including positive outcomes for branding, the ability to attract competent workers, the avoidance of accusations of discrimination and sexism, or the provision of goods and services that were better adapted to customers. Several consultants expressed the following sentiment: 'People have to see, "what's in it for me." The consultants were intent on demonstrating that gender equality is consistent with or in line with the goals of the client's organisation. The consultants' work assignments thus entailed the erasure of any possible conflicts between their approach and the goals of the organisation in order to achieve a seamless win-win strategy. However, as suggested by Elisabeth, emphasising (financial) gain was merely 
a way of getting a client interested in what the consultant could offer. Thus, the theme of financial gain was 'smuggled' into the initial conversations with the client (cf. Petersson McIntyre, 2015).

Elisabeth: I often refer to research, say it has been shown that equality is profitable, but for me, it is a way of getting them to work with equality. A means to get these issues through. I don't just do it for them to make money. I do it so they become more equal because I believe it is a good thing.

From this perspective, talk of profit may also be seen as a way of talking about gender equality that does not imply an actual standpoint. In fact, it can be understood as part of developing a new language of economics which has the purpose of allowing the client to imagine new ways of understanding profits.

According to Elisabeth, it is no longer necessary to emphasise the potential profits that can be gained from gender equality because most people accept that equality is important and has value in an economic context. This idea was mentioned in several interviews. For example, Elvira observed that, 'Profit, to motivate gender equality with profitability felt like an old argument.' Elsa expressed a similar sentiment:

When we work with recruitment, the profit focus is very clear. We say, 'Well, we try to help you find the right competence faster, so the recruitment processes don't become too drawn out and expensive. We help you to create a good workplace culture, so you don't need to recruit again because people quit because they don't like it.

Elsa continued by saying that these matters rarely need to be explicitly articulated, 'they are understood'. Many of the consultants even said that with respect to profit, 'maybe a few years ago you needed to say it, now firms know', or 'you don't need to talk profit anymore!' Consequently, talk of profit does not only have to be interpreted as evidence of neoliberal rationality; it may also be a way for activists to introduce some degree of innovation to their cause — to counter-perform the economy — by filling the word profit with new meaning.

\section{Solution Focus}

Another popular technique used by the consultants was to emphasise positivity. "Always focus on "the positive", always focus on solutions. You have to be positive to make it work." ${ }^{7}$ Even if positive thinking is encouraged in many fields, the meaning and effects are specific when it used in the context of gender issues. As Doris put it:

It is interesting to talk of profit, and those arguments will always be important, like: 'Did you know that it is like this and that, and you will make more money if you do this instead?' But there are other arguments that are more interesting. Work environment, sustainability, keeping people from 'burn-out', those arguments are trending now, and innovation, not profit, but innovation. Contribute to the development, new ideas, have women design cars. It should be fun, sustainable, inventive, and exciting!

Several other consultants emphasised the importance of being 'constructive', and talked about innovation in a manner similar to Doris above. The idea of having women design cars is however not a new one. Women have been involved as designers in the car industry both to accommodate 'feminine taste' (Sparke, 1995), and to challenge male bias in car design (Petersson McIntyre, 2010; 2015; 2018). Yet, the idea that inequalities are perpetuated by badly-designed products and organisations and can be 'fixed' has perhaps grown stronger alongside the development of firms that offer solutions to these problems.

During a workshop for new consultants, a consultant trainer exhorted the workshop attendees to 'always be productive' and 'embrace difficulties, they will make you stronger and more skilled'. ${ }^{8}$ Challenges were described as something positive, that could be used by the consultants to develop an innovative approach to the field. 'Norms' were talked about as something that should not be crushed, or destroyed, but exchanged for other norms that can help people achieve their best potential. Some of the informants even expressed a form of technicalisation of gender issues, for example,

I was asked once, 'What drives me?' And I want things to work. And it doesn't if it is unfair in any way. I don't know if I am making any sense? ... It should be easy for people to solve their tasks and get on and to be able to make money and have the opportunity ... to feel good. That is what I think ... You feel good when things work. I am more pragmatic; I want things to work in a technical sense (Doris).

Inequalities were often described as non-functional; a predicament that could be changed with the right way of thinking. To find solutions and to be 'solution-oriented' was an approach shared by many of the consultants,

\footnotetext{
${ }^{7}$ From the author's field notes.

${ }^{8}$ From the author's field notes.
} 
especially those who primarily work in the private sector. Similarly, if a company had an issue concerning their equality image, consultants were invited to 'solve' the issue, but not to point to problems, question the organisation, or the framing of the issue at hand. They were asked not 'to point fingers' or to 'put blame' on anyone or the organisations, but, instead, to be positive, engaging and constructive. One senior consultant remarked, during my fieldwork and in the context of discussing how new consultants should respond to a client: 'Well, maybe it is not their [the client's] job to save the world'. Kantola and Squires (2012) suggest that statements like this illustrate that a market enables some forms of gender business, but not others. Only 'solutions' could be 'sold' as a commodity on the market; 'critique', without practical or material solutions, had no apparent value. Thus, 'innovation' is a term that accurately captures this way of thinking since it invokes the idea that innovations can solve problems.

As a term, innovation is often related to ideas of 'improvement' and 'progress'. In the process of 'fixing' nonfunctional norms, appreciating the role that gender and gender equality play is generally motivated in conjunction with something else - such as optimising an organisation by creating a win-win situation. This process is part of a narrative in which inequality is described as ineffective and harmful, but also where striving for equality becomes a project for the self. However, the process may also be understood as an illustration of the potentials in the field of gender work, and as one step in counter-performing the market. In this process, the consultants constantly had to innovate their products and services in order to participate in the field.

\section{Feeling Equal}

Being a feminist entrepreneurial subject involves engaging one's body, feelings and mind in one's occupation in several ways. Often, the notion of 'fun' was part of being an entrepreneurial subject, along with 'feeling good'. These dimensions were set in opposition to suffering from mental illness, feeling burnt-out and exhaustion syndromes - pathologies that were often brought up by the consultants (cf. Gill, 2016). The consultant Sara argued: 'The whole reason for doing this is this thing. Desire, inspiration, creativity, making your own assignments, forming them so people understand. I take inspiration from everyday life.'

However, the processes of turning issues of gender and feminism into marketable products often entailed mixed emotions in the consultants. A significant number of compromises had to be made on the way, and the consultants felt that this was far from straightforward: 'Selling one's soul' was regularly mentioned during the interviews. Many of the consultants had asked themselves: 'Where do you draw the line?' The consultants had to convince their clients that the products they were selling were good for the former's business, but they also always had to convince themselves that consultancy work for private companies was in line with their feminist convictions. Often, the jobs that they were commissioned to perform were not really that great, the consultants said, and they were not always convinced that they were doing the right thing. Their own ideas, ideals and beliefs had to be streamlined and modified so that they were in line with the client's goals and visions. Many described this process as difficult and painful on a personal level. Michael shared his thoughts on this issue thus:

The act of translation implies a de-radicalisation. 'Power' [as a concept] is sorted out, and you stop using 'equality' as a means to 'disrupt' an order, and start using it to 'support' an order, that which is going to be kept. It is these little dislocations. I have thought a lot about that. [...] Sometimes, you start hating yourself.

However, 'being positive' was an attitude that was expected from clients as well as from the consultants. Several consultants remarked that 'clients need to "feel"' and 'change is accomplished with the heart, not with the brain'. Emphasising the domain of emotions and feelings, the consultants expressed that something more significant, more than just optimising organisations and increasing corporate efficiency, was at stake. This was characterised as a way of changing direction, not just for one's own goals, but for one's clients' goals too. Werner (2015: 87), drawing on Gibson-Graham (2006: 129), talks of mobilising the emotion of 'desire' to build enterprises that dislodge the emotional investment in capitalism.

Similarly, Healy argues that in order to assemble 'community economies', we must also come to desire them: 'Coming to desire noncapitalism involves believing that it is a possibility and then shifting one's desires away from the usual way of imagining ourselves in relation to the economy (Healy, 2015: 105). This includes ' $a$ ] shift in desire that establishes an affective opening to other economies and noncapitalist possibilities' (Healy, 2015: 105). Involving emotions can be a matter of pushing norms of what is expected, and of shifting desires while at the same time embracing a neoliberal subjectivity in which all aspects of life become a resource for entrepreneurship. These processes were not clear-cut in the professional lives of the consultants. For example, being paid for one's work was often understood as a feminist matter in itself:

These questions [gender equality] become more and more important. Of course, previous generations worked with these issues too, but it was often on a non-profit basis. You were meant to see it as a calling. You are supposed to work for free. Save the world and so on! (Paula). 
The consultants' reasons for wanting payment for their work were not only a matter of making a living but also the result of adopting the standpoint that equality work has as much economic value as anything else in the world. Thus, even if gender consultancy does not instantiate a clean break with capitalism, in many ways, it is quite the opposite. Many of the consultants still had the ambition to reformulate the narratives of capitalism by insisting that gender issues have a necessary place in business. This approach to the financial aspects of their work constituted a way of forming an empowered subject since the consultants questioned and challenged boundaries of the economy and refused to participate in the gender culture which informs women's work in a public sector that has subordinated women, segregated the labour market, offered women lower wages, caused high levels of illness in women, and less generous career development pathways than men who work in private industry.

\section{Together in Ways that Matter}

Gibson and Scott (2019) argue that economies should be reframed in terms of things that matter to people, including living a good life. We should ask ourselves how the narratives around economies stand in the way of thinking about finance differently, and we should engage in what they refer to as 'counter-hegemonic projects' to promote a 'collective disidentification' with the ideological fantasy of capitalism (Gibson and Scott, 2019; GibsonGraham, 2006: 55-56).

Several of the consultants described their business idea as a way of working together in ways that matter:

Elsa: We don't want to reproduce destructive work relations, competitiveness, and burn-out. We want to find new ways of doing it together. Work together to question the 'alone/unique male genius'.

The consultants often felt that prevailing business models encouraged specific ways of thinking. For example, the rules that govern and regulate public procurement were viewed as a problem for many of the consultants, because the rules prevented them from making offers to certain public sector organisations due to the size of their company or their workload. The economic system thus often entailed that these consultants were subject to certain limitations. Consequently, many of them felt that new business models were needed where they would not have to compromise so much with their personal goals and ambitions, and where their business decisions could be based on ethical commitments.

The consultants reported that it was essential to 'practice what you preach'. Some of the interviewees had wanted to find ways of running a business that were both 'more fun' and could function as a means of getting away from freelancing and 'gigging', and, instead, could provide more security. Whilst the consultants wanted the opportunity to work with questions that they found meaningful, their goal was not to accumulate wealth (Snyder and Martin, 2015: 46).

Doris: We don't want to stand alone and try [to make it work]. Let's unite in a commune [ett kollektiv]. Let's support and help each other.

Elsa: In the gig economy, you have to keep things to yourself, and that is not good. It does not create organisations that forward knowledge. You keep your knowledge to yourself. It doesn't lead to positive development. Neither intellectually nor financially. And it doesn't make society any better either; it just takes too long.

Elvira: It goes against our ideas of doing things together, thinking that it should be fair and nice and so on. We work to include, etc. And, at the same time, we elbow ourselves past others to [get contracts]. In my world, that doesn't add up.

Even if the ideas expressed in the above extracts seem somewhat utopian and clash with the reality of having to put food on the table or to compete for clients, they show that the consultants shared an ambition of thinking in new ways. This attitude provides a 'taste of communality' and 'an important part of nurturing and cultivating noncapitalist subjectivities through gradual and sudden shifts in feeling and embodiment' (Werner, 2015: 83). This claim resonates with the idea of being 'affected by the process of collective action' (Healy, 2015: 116).

Magdalena: So you are saying that the organisation of your company is a form of innovation?

Group of Consultants: Oh, god yeah! And a very ideological act [ideologisk handling]. It is like standing on the barricades.

Magdalena: Can you add to this description — that it is an act of ideology?

Group of Consultants: Well, it is a questioning of the ideas; it is stretching boundaries of societal norms of the economy, the ways things are supposed to be, how they should work. How one should work. 
When one should work. Why one should work. But not just that. It is the whole system, the way it looks today.

Just like gender equality, this reorientation towards the system was often talked about in the form of improvements. Competition within the prevailing system was described as something negative because it is ineffective. This reflection of the innovation discourse may be seen as an expression of the pervasiveness of neoliberal rationality; even the barricade itself is thought of as a market. However, referring to business practice as 'the barricades' may also signal a way of renewing the meaning of 'innovation', a way of taking control of definitions, and an attempt to transform the masculine narrative of innovation. This may entail turning the market against itself, and trying to transform capitalism from within while using its own language and form to give the language of capitalism new meanings.

\section{Market Innovation}

The attitudes described in the previous section were indicative of how many of the consultants had thought about alternative ways of organising their firms. Even though most firms only employed one person, there were a couple of firms that employed four individuals. Some of these had tried to come up with ways of organising themselves like 'a commune'.

We have a limited company. But the way we work, it is a commune. Everyone gets paid the same. We back each other up when it is needed. [...] We are all equally involved in everything. We have to, to be ready if someone gets ill, or has a sick child. Whatever happens. Our whole idea builds on solidarity and sisterhood. We want to try to practice what we work with [practice what we preach] or offer as services.

The consultants described their manner of working together in the following way: when a work assignment was awarded to an individual, this person might hesitate to ask a colleague for help and advice because the colleague might then want a share of the hours that had been allocated to the work assignment. To move away from such inward-looking work relations, some of the consultants decided to work cooperatively together and share their work assignment hours, and create more stable employment opportunities, instead of working as self-employed individuals on ad hoc individual work assignments. This arrangement allowed these consultants to fulfil the requirements needed to be entitled to sick-pay that is paid by the Swedish social insurance system. The consultants thus created a joint limited company that employed them all of them on the same salary. Self-employment was not a goal for them. Instead, self-employment was something they wanted to get away from in order to benefit from the social security safety net that the Swedish state offers to employees. As Elvira put it:

Say you work $40 \%$ effective time per month. If we create a full-time post based on your earnings for $40 \%$, then you still get an okay salary, and we have fooled the social security system. Well, it is not about fooling anyone; we didn't get any money off the system. But we say: 'Fine; we get nothing from you, so we don't give a shit about you!' Sorry! This is feminism for real. If losing sick-pay stops us from starting a business, that is awful.

The extract above illustrates the performative nature of economic knowledge. Mapping out economic relations allowed some of the consultants to perform those relations as economic to their benefit. The consultants' discussions revolved around (i) the generation and use of financial surplus, (ii) how to create well-being, and (iii) how to use shared assets (see Werner, 2015: 78). Even if the consultants' businesses and economic turnover were small, knowledge about them opened up what Werner calls 'economic imaginaries and [performances of] new worlds' (Werner, 2015: 78). Viola touched on this idea:

It is supposed to be organised in a certain way, and we have taken outer pieces and built our company in a different way. That, in itself, is a comment on the fact that we were unhappy with the way things usually worked or were organised previously.

In a manner similar to the way the idea of 'togetherness' was discussed, 'social security' was also talked about in terms of increased efficiency. One consultant remarked that:

Motivation increases when there is security. Otherwise, you have to try to grab as many hours as you can. But when you feel that others are prepared to help you out, then you get motivated to help them back.

Thus, similar to the idea of 'togetherness', an innovation can take control of work relationships. The consultants argued that they were unhappy with how companies were expected to be organised, but all the while, 'a "gender 
consultant" is morally and ethically obliged to contribute to this work. The alternative is no longer possible; we cannot watch and stand aside. We want to use our competence to make a difference."9

\section{CONCLUSION}

In this article, I have discussed the commodification of gender equality in the context of gender equality consultancy work. The increased demands for gender equality to be profitable are quite clearly entangled in innovation discourse because capitalist growth is driven by the introduction of new products and services (Beckert, 2016). During my fieldwork and during the interviews that I conducted with the consultants, innovation discourse manifested itself in the demands that the consultants felt were being placed on them. These demands included being innovative, being able to suggest improvements and having to design new products and services. Moreover, the interviewees also wanted to innovate the form and content of their communication so that they could better explain the importance of gender issues and sell their services. This was something they did by creating new products, thinking up new words and concepts, and by emphasising what the client could gain from the consultants' work. They also searched for new ways of organising their work with economic innovations; I have termed this 'together in ways that matter'. I also analysed the double meaning of innovation in this context. On the one hand, the impact on innovation discourse was visible in consultants' work and the ways they made sense of their activities. On the other hand, the consultants struggled to fill this term with new meanings that corresponded to their own personal views on gender equality and their ideals of living a meaningful life. I argue that the use of words and terms that are taken from corporate life, innovation systems, and the domain of optimising and maximising profits and organisations can be evidence of the impact of neoliberal discourses on how everything can be organised in the form of a market. However, the consultants' use of these terms also suggests a way of associating new meanings with these terms, of opening up and creating alternative ways of understanding and doing gender issues, commercially on the market, and to imagine the economy in new ways. Some of the interviewees had succeeded in putting their economic innovations into practice by rethinking the use of surplus, sharing assets and creating well-being, they had found a way of organising themselves in ways that they felt mattered.

I analysed the consultants' engagement in business and innovation discourse as ways of counter-performing or countermanding the gendered narratives of economics, private industry and innovation. The consultants questioned (misguided) ideas that gender issues are 'soft values' that should be paid for by the state or public sector. Their activities were thus deployed in creating a rift in the gendering of innovation discourse, and we may thus begin to deconstruct certain dominant narratives by developing a new language of economics. This perspective opens up a view of capitalism as performative, as something that is made, not something that is. By adopting this perspective, the consultants' activities staked out a path for change, and opened up discussions of more ethically grounded ways of organising work in ways that matter. By innovating their business models, the consultants showed that conventional business models can be reconfigured. Thus, as well as delineating ways by which definitions of economic practice can be redefined, this perspective also helps to shift the course toward more equal ways of organising society. Instead of focusing on how neoliberalism produces the entrepreneurial self, the focus can be shifted to examining the possibilities for the formation of a self that is desirous of an economy that matters.

Instead of seeing the consultants' explanations of what they do as an adaptation of a market form that is merely modelled on corporate life, I have analysed them as one step towards countermanding the market. Their descriptions were illustrative of their constant reworking of their feminist ideals to a functioning reality. I analysed consultants' emotional investments in their products and services, and conclude that these investments can be interpreted as a shift in desire that opens up to other possibilities of doing feminist entrepreneurialism. Given this, the reader should note that in this article I have not focused on evaluating the success of feminism in a market setting (cf. Kunz and Prügl, 2019), but, instead, I have focused on the feminist agencies that the commodification of feminism allows for. The interviewees reported that they were encouraged, by themselves and others, to create an entrepreneurial self. However, during this process of creating an entrepreneurial self, they resisted becoming merely an iteration of the usual capitalist entrepreneur, in favour of a self that worked together with others in ways that matter. When entrepreneurial or business success is measured by the ability to create an equal world, rather than the ability to generate economic turnover or a share dividend, a different economic subjectivity is created. Concern for an equal world, of course, poses a challenge to definitions of 'the economy', but may well allow the creation of more feminist economies and the opening up of a space where innovation may find a different place and function.

\footnotetext{
${ }^{9}$ From the author's field notes.
} 


\section{REFERENCES}

Ahl, H., Berglund, K., Pettersson, K. and Tillmar, M. (2016). From Feminism to FemInc.ism: On the Uneasy Relationship Between Feminism, Entrepreneurship and the Nordic Welfare State. International Entrepreneurship \& Management Journal, 12(2), 369-392. https:// doi.org/10.1007/s11365-014-0341-4

Alnebratt, K. and Rönnblom, M. (2016). Feminism som byråkrati [Feminism as bureaucracy]. Stockholm: Leopard.

Beckert, J. (2016). Imagined Futures: Fictional expectations and capitalist dynamics. Cambridge, Mass.: Harvard University Press. https://doi.org/10.4159/9780674545878

Berglund, K., Ahl, H., Pettersson, K., Tillmar, M., et al. (2018). Women's Entrepreneurship, Neoliberalism and Economic Justice in the Postfeminist Era: A Discourse Analysis of Policy Change in Sweden. Gender, Work and Organization, 25, 531-556. https:// doi.org/10.1111/gwao.12269

Brown, W. (2003). Neo-Liberalism and the End of Liberal Democracy. Theory \& Event, 7(1). https://doi.org/10.1353/tae.2003.0020

Butler, J. (1990). Gender Trouble. New York: Routledge.

Callon, M. (1998). The Laws of the Market. Oxford: Blackwell.

Cameron, J. (2015). Enterprise Innovation and Economic Diversity in Community-Supported Agriculture: Sustaining the Agricultural Commons, in G. Roelvink, K. St. Martin and J. K. Gibson-Graham (eds), Making Other Worlds Possible: Performing diverse economies (pp. 53-71). Minneapolis: University of Minnesota Press. https://doi.org/10.5749/j.ctt130jtq1.6

Cochoy, F., Giraudeau, M. and McFall, L. (2014). The Limits of Performativity. London: Routledge. https://doi.org/10.4324/9781315776644

De Los Reyes, P. (2016). When Feminism Became Gender Equality and Anti-racism Turned into Diversity Management, in L. Martinsson, G. Griffin and K. Giritli Nygren (eds), Challenging the Myth of Gender Equality in Sweden (pp. 23-48). Bristol: Policy Press. https:// doi.org/10.1332/policypress/9781447325963.003.0001

De Los Reyes, P. and Mulinari, D. (2005). Intersektionalitet. Kritiska reflektioner över (o)jämlikhetens landskap [Intersectionality: Critical reflections on the landscape of (in)equality]. Malmö: Liber.

Dworkin, S. and Wachs, F. (2009). Body Panic: Gender, health, and the selling of fitness. New York and London: New York University Press.

Ehn, B. and Löfgren, O. (2009): Ethnography in the Marketplace. Culture Unbound, 1, 31-49. https:// doi.org/10.3384/cu.2000.1525.091431

Ehn, B., Löfgren O. and Wilk, R. (2016). Exploring Everyday Life: Strategies for ethnography and cultural analysis. Lanham: Rowman and Littlefield Publishers.

Gibson, K. and Scott, S. (2019). Language, Gender and Crisis: An Interview with Katherine Gibson. Journal of Cultural Economy, 12(5), 448-460. https:/ / doi.org/10.1080/17530350.2018.1542609

Gibson-Graham, J. K. (ed). (2006). A Postcapitalist Politics. Minneapolis: University of Minnesota Press.

Gill, R. (2016). Post-Postfeminism? New Feminist Visibilities in Postfeminist Times. Feminist Media Studies, 16(4), 610-630. https://doi.org/10.1080/14680777.2016.1193293

Healy, S. (2015). Biofuels, Ex-Felons, and Empower, a Worker-Owned Cooperative: Performing Enterprises Differently, in G. Roelvink, K. St. Martin and J. K. Gibson-Graham (eds), Making Other Worlds Possible: Performing diverse economies (pp. 98-126). Minneapolis: University of Minnesota Press. https://doi.org/10.5749/j.ctt130jtq1.8

Kantola, J. and Squires, J. (2012). From State Feminism to Market Feminism. International Political Science Review, 33(4), 382-400. https://doi.org/10.1177/0192512111432513

Kunz, R. and Prügl, E. (2019). Introduction: Gender Experts and Gender Expertise. European Journal of Politics and Gender, 2(1), 3-21. https://doi.org/10.1332/251510819X15471289106077

Lewis, P., Benschop, Y. and Simpson, R. (2017). Postfeminism, Gender and Organisation. Gender, Work \& Organisation, 24(3), 213-225. https:// doi.org/10.1111/gwao.12175

Lindberg, M. (2017). Promoting and Sustaining Rural Social Innovation. European Public \& Social Innovation Review, 2(2), 30-41. https://doi.org/10.31637/epsir.17-2.3

Martinsson, L., Griffin, G. and Giritli Nygren, K. (eds). (2016). Challenging the Myth of Gender Equality in Sweden. Bristol: Policy Press. https://doi.org/10.1332/policypress/9781447325963.001.0001

McRobbie, A. (2009). The Aftermath of Feminism: Gender, culture and social change. London: Sage.

Negra, D. and Tasker, Y. (eds). (2007). Interrogating Post-Feminism: Gender and the politics of popular culture. Durham: Duke University Press. https:// doi.org/10.2307/j.ctv1210217

Olivius, E. and Rönnblom, M. (2019). In the Business of Feminism: Consultants as Sweden's New GenderEquality Workers. European Journal of Politics and Gender, 2(1), 75-92. https://doi.org/10.1332/251510819X15471289106103 
Petersson McIntyre, M. (2014). Commodifying Passion: The Fashion of Aesthetic Labour. Journal of Cultural Economy, 7(1), 79-94. https:// doi.org/10.1080/17530350.2013.851029

Petersson McIntyre, M. (2015). Queering All Aboard: Challenging the Maleness of the Leisure Boat Industry. International Journal of Entrepreneurship and Small Business, 24(1), 4-22. https://doi.org/10.1504/IJESB.2015.066161

Petersson McIntyre, M. (2018). Gender By Design: Performativity and Consumer Packaging. Design and Culture, 3, 337-358. https://doi.org/10.1080/17547075.2018.1516437

Pink, S., Horst, H., Postill, J., Hjorth, L., Lewis, T. and Tacchi, J. (2016). Digital Ethnography: Principles and practice. London: Sage.

Roelvink, G., St. Martin, K. and Gibson-Graham, J. K. (eds). (2015). Making Other Worlds Possible: Performing diverse economies. Minneapolis: University of Minnesota Press. https://doi.org/10.5749/j.ctt130jtq1

Scharff, C. (2016). The Psychic Life of Neoliberalism: Mapping the Contours of Entrepreneurial Subjectivity. Theory, Culture and Society, 33(6), 107-122. https:// doi.org/10.1177/0263276415590164

Scharff, C., Smith-Prei, C. and Stehle, M. (2017). Digital Feminisms: Transnational activism in German protest cultures. London: Routledge. https:// doi.org/10.4324/9781315406220

Sparke, P. (1995). As Long as It Is Pink: The sexual politics of taste. London: Rivers Oram Press.

Wajcman, J. (2004). TecbnoFeminism. Cambridge: Polity Press.

Werner, K. (2015). Performing Economies of Care in a New England Time Bank and Buddhist Community, in G. Roelvink, K. St. Martin and J. K. Gibson-Graham (eds), Making Other Worlds Possible: Performing diverse economies (pp. 72-97). Minneapolis: University of Minnesota Press. https://doi.org/10.5749/j.ctt130jtq1.7

Citation: Petersson McIntyre, M. (2021). Back on the Barricades: New Feminisms and Market Innovation in the Consultancy Field. Feminist Encounters: A Journal of Critical Studies in Culture and Politics, 5(2), 23. https://doi.org/10.20897/femenc/11159

Copyright (C) 2021 by Author/s and Licensed by Lectito BV, Netherlands. This is an open access article distributed under the Creative Commons Attribution License which permits unrestricted use, distribution, and reproduction in any medium, provided the original work is properly cited. 